\title{
Covered conductor burn-down prevention for distribution line in Indonesia
}

\author{
Putu Agus Aditya Pramana ${ }^{1, *}$, Aristo Adi Kusuma ${ }^{1}$, Buyung Sofiarto Munir ${ }^{1}$, and Handrea Bernando Tambunan ${ }^{1}$ \\ ${ }^{1}$ PLN Research Institute, Transmission and Distribution Department, 12760 Jakarta, Indonesia
}

\begin{abstract}
Covered conductor (CC) is used to resolve temporary line to ground fault in the distribution line. However, some cases of $\mathrm{CC}$ burn down were found in Indonesia. These phenomena were triggered by lightning strikes that cause transient overvoltage with a magnitude greater than basic insulation level (BIL) of insulator. Consequently, short circuit current will flow through the pinhole on CC. Burn down phenomena will create high impedance fault that is unable to be detected by protection relay, thus the conductor will remain energized and harmful to the surroundings. Therefore, this paper presents study about $\mathrm{CC}$ burn down prevention. The study was performed using transient simulation to find the effect of earth wire utilization against the transient overvoltage due to lightning strike. In addition, finite element simulation and laboratory testing were also performed to analyze the effect of power arc device on burn down prevention. The results show that the lightning strike with negative polarity will not cause transient overvoltage with a magnitude greater than the insulator BIL. However, if the lighting strikes have positive polarity then the insulator BIL will be potentially exceeded. Furthermore, the utilization of power arc device will prevent the $\mathrm{CC}$ burn down.
\end{abstract}

\section{Introduction}

Covered conductor $(\mathrm{CC})$ is used to resolve temporary line to ground fault in the distribution line. However, some cases of CC burn down were found in Indonesia. These phenomena were triggered by lightning strikes that cause transient overvoltage with a magnitude greater than basic insulation level (BIL) of insulator. Consequently, short circuit current will flow through the pinhole on CC. Burn down phenomena will create high impedance fault that is unable to be detected by protection relay, thus the conductor will remain energized and harmful to the surroundings $[1,2,3,4,5,6]$. Therefore, this paper presents study about CC burn down prevention. The study was performed using transient analysis simulation to find the effect of earth wire utilization against the transient overvoltage due to lightning strike. In addition, finite element simulation and laboratory testing were also performed to analyze the effect of power arc device on burn down prevention.

\section{Effect of lightning on covered conductor}

\subsection{Protection angle and lightning current calculation}

There are some distribution line which is not protected by the ground wire in Indonesia, so that when the lightning strike happened, the phase wire is potentially experience the direct strike. The utilization of ground wire can reduce the direct strike on conductor phases [7]. To simulate the effect of ground wire utilization while facing the lightning strike, first the protection angle should be calculated. the magnitude of lightning current which is possible to strike the phase is given by (1) and (2) [8].

$$
\begin{gathered}
\sin \alpha=(1-H) / r \\
r=10 I^{0.65}
\end{gathered}
$$

$\alpha$ is protection angle (degree), $H$ is pole height $(\mathrm{m}), r$ is striking distance (m), and $I$ is the lightning current (A).

In the distribution line which protected by the ground wire, the larger magnitude of lightning current tend to strike the ground wire. However, the smaller one tends to hit the phase conductor because of shielding angle failure.

\subsection{Surge impedance of pole}

In the transient analysis of lightning strike, pole is modelled as a path for surge propagation. Therefore, the calculation of pole surge impedance is an important factor in analyzing the effect of lightning strike. Surge impedance of the pole is calculated using (3). $H_{c}$ is pole height $(\mathrm{m}), r_{c}$ is pole diameter $(\mathrm{m})$, and $Z_{c}$ is surge impedance of pole.

\footnotetext{
* Corresponding author: putu.pramana@pln.co.id
} 


$$
Z_{\text {Pole }}=60 \ln \left(2 \sqrt{2} \frac{H_{c}}{r_{c}}\right)-60
$$

\section{Simulation}

The method to prevent the covered conductor burndown is by using ground wire on the distribution line. In this part, the simulation of transient over voltage in the isolator has been performed. The simulation was

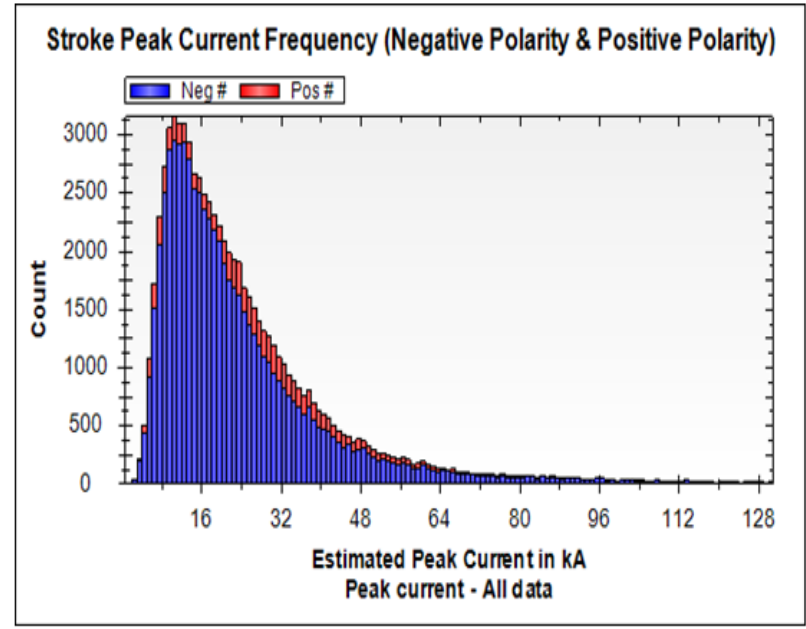

Fig. 1. The lightning characteristic.

Figure 1 shows that the negative polarity lightning has the mode value about $11 \mathrm{kA}$ and the positive polarity lightning has the mode value about 23kA. These negative and positive values are used in the simulation in the first scenario and second scenario. The simulation assumes that the rise time and tail time of lightning voltage produced by lightning current is about $1.2 \mathrm{us}$ and 50us, respectively. performed using three scenarios of lightning strike. The first scenario is proposed to simulate the effect of lightning strikes on the phase wire when distribution line had no ground wire. The second scenario is proposed to simulate the effect of lightning strikes on the phase wire when distribution line had ground wire. The third scenario is proposed to simulate the effect of lightning strikes on the ground wire when distribution line had ground wire. The lightning characteristic which is used in this simulation is given by Figure 1.

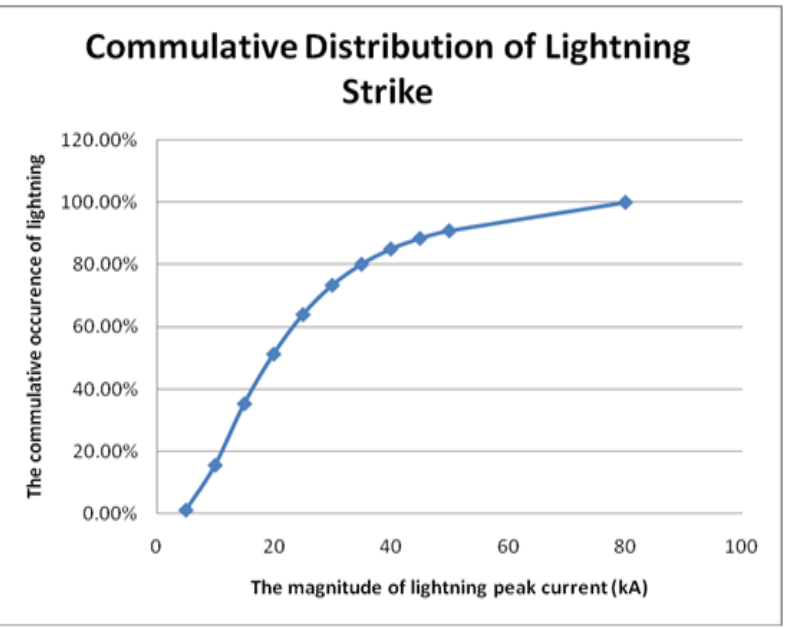

\subsection{Lightning Strike on phase when the line without ground wire}

The simulation for the first scenario (lightning strikes on the phase wire when distribution line had no ground wire) using the model given in Figure 2.

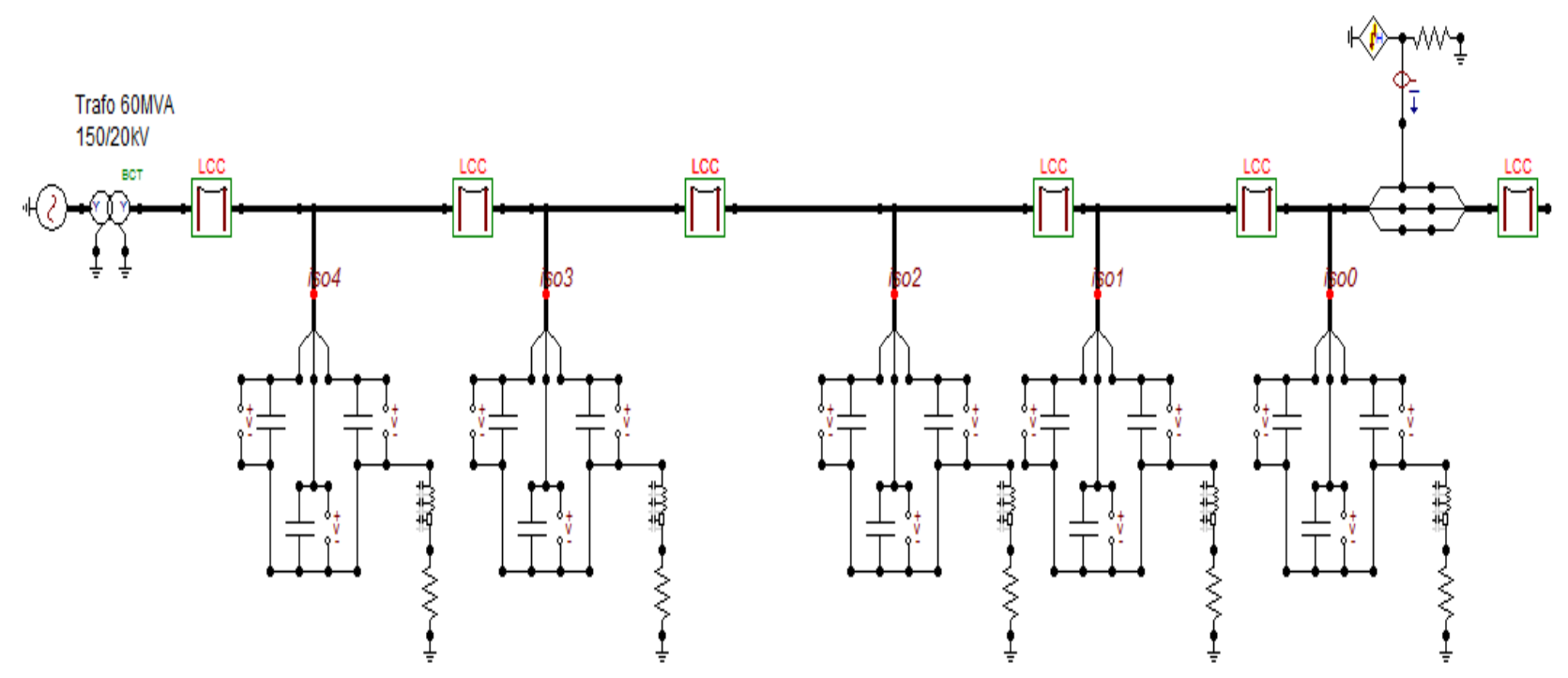

Fig. 2. Model for lightning simulation for distribution line without ground wire. 
Using the model in Figure 2, the simulation result when the negative polarity lightning current stroked the phase is given in Figure 3.
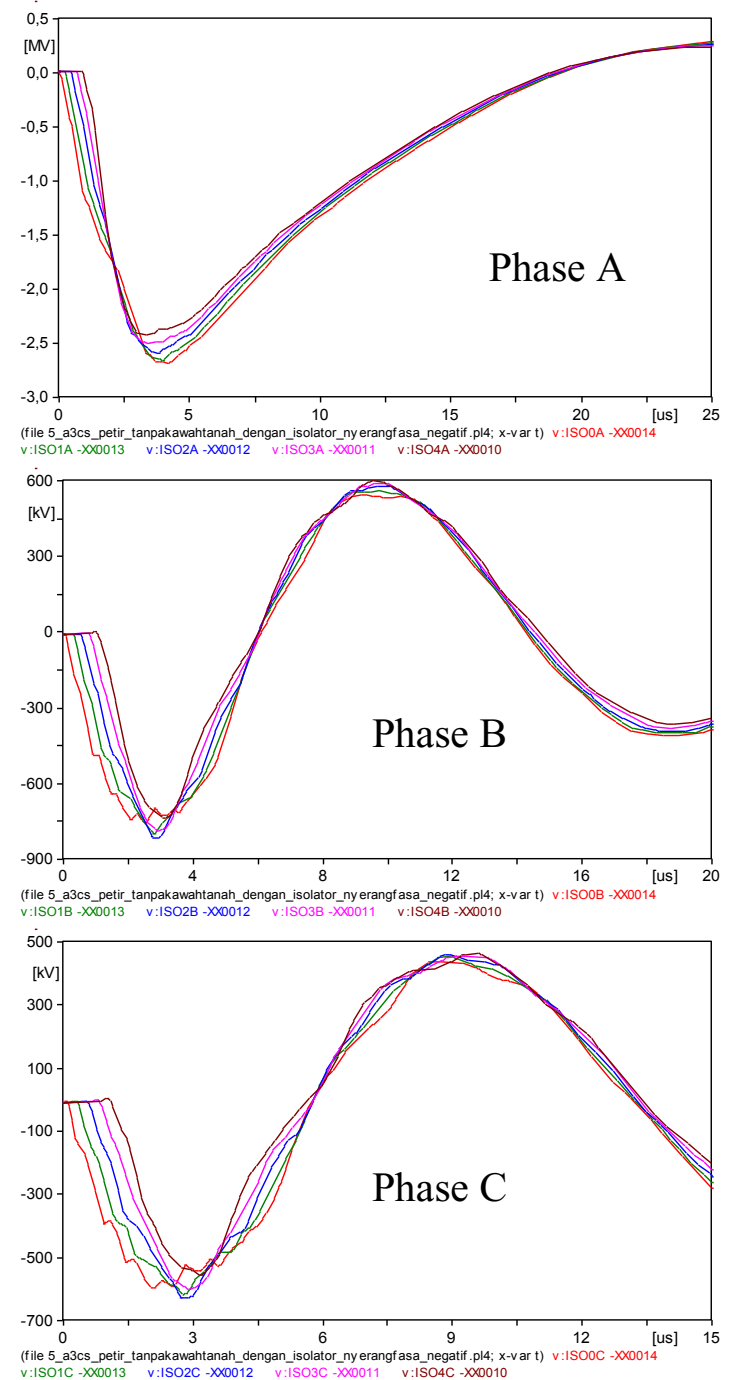

Fig. 3. Overvoltage of negative polarity lightning current strike on distribution line without ground wire.

Figure 3 presents the voltage dynamic that occur across the isolator for Phase A, phase B, and phase C, respectively when the negative polarity lightning current stroked the phase A. Maximum voltage value for phase $\mathrm{A}$, phase $\mathrm{B}$, and phase $\mathrm{C}$ are $2.7 \mathrm{MV}, 700 \mathrm{kV}$, and $600 \mathrm{kV}$, respectively. V:ISO0 in the graphic represents the voltage dynamic in the line span that is stroked by the lightning, V:ISO1 in the graphic represents the voltage dynamic in the one line span distance from the strike point, V:ISO2 in the graphic represents the voltage dynamic in the two lines span distance from the strike point, and so on for the V:ISO4 and V:ISO5. Then, simulation results for the lightning strike simulation with positive lighting polarity is given in Figure 4.
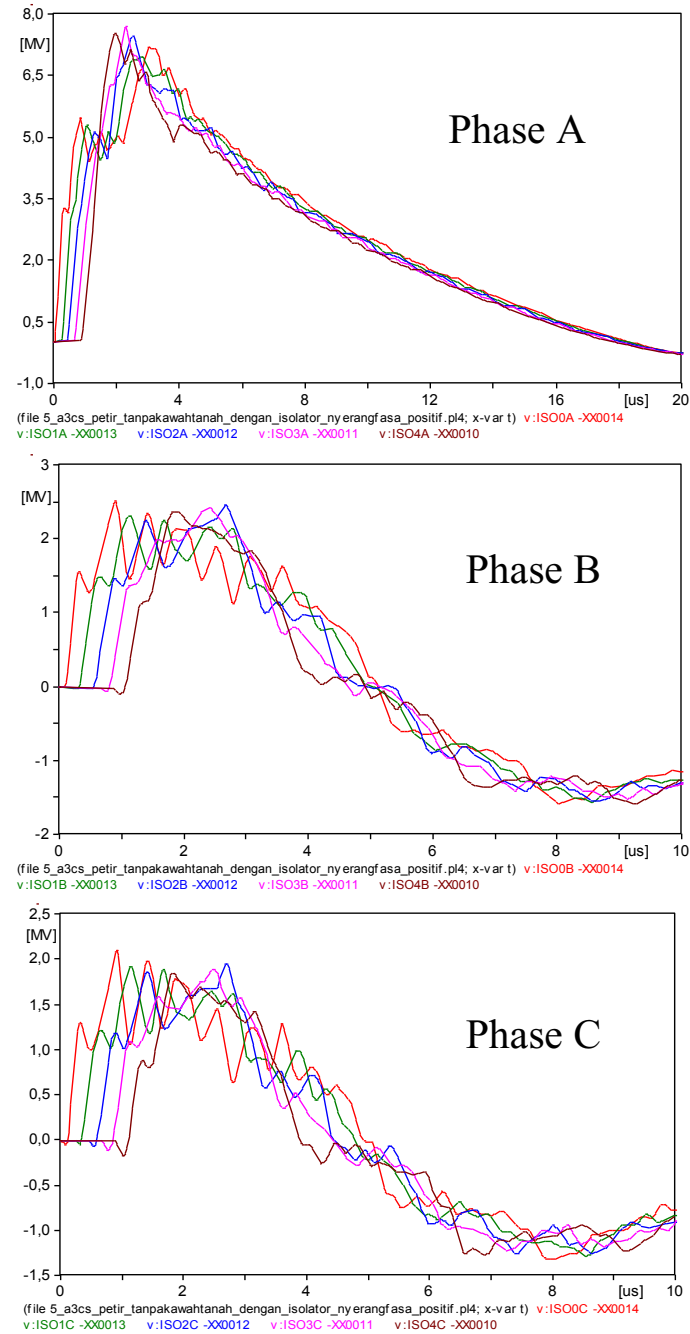

Fig. 4. Overvoltage of positive polarity lightning current strike on distribution line without ground wire.

Figure 4 presents the voltage dynamic that occur across the isolator for Phase A, phase B, and phase C, respectively when the positive polarity lightning current stroked the phase A. Maximum voltage value for phase $\mathrm{A}$, phase $\mathrm{B}$, and phase $\mathrm{C}$ are $8 \mathrm{MV}, 2.5 \mathrm{MV}$, and $2 \mathrm{MV}$, respectively. V:ISO0 in the graphic represents the voltage dynamic in the line span that is stroked by the lightning, V:ISO1 in the graphic represents the voltage dynamic in the one line span distance from the strike point, V:ISO2 in the graphic represents the voltage dynamic in the two line span distance from the strike point, and so on for the V:ISO4 and V:ISO5.

\subsection{Lightning Strike on phase and ground wire when the line completed with ground wire}

The simulation is continued to show the overvoltage characteristic when the distribution line had ground wire. The simulation is performed using the model given in Figure 5.

\footnotetext{
*Corresponding author: putu.pramana@pln.co.id
} 


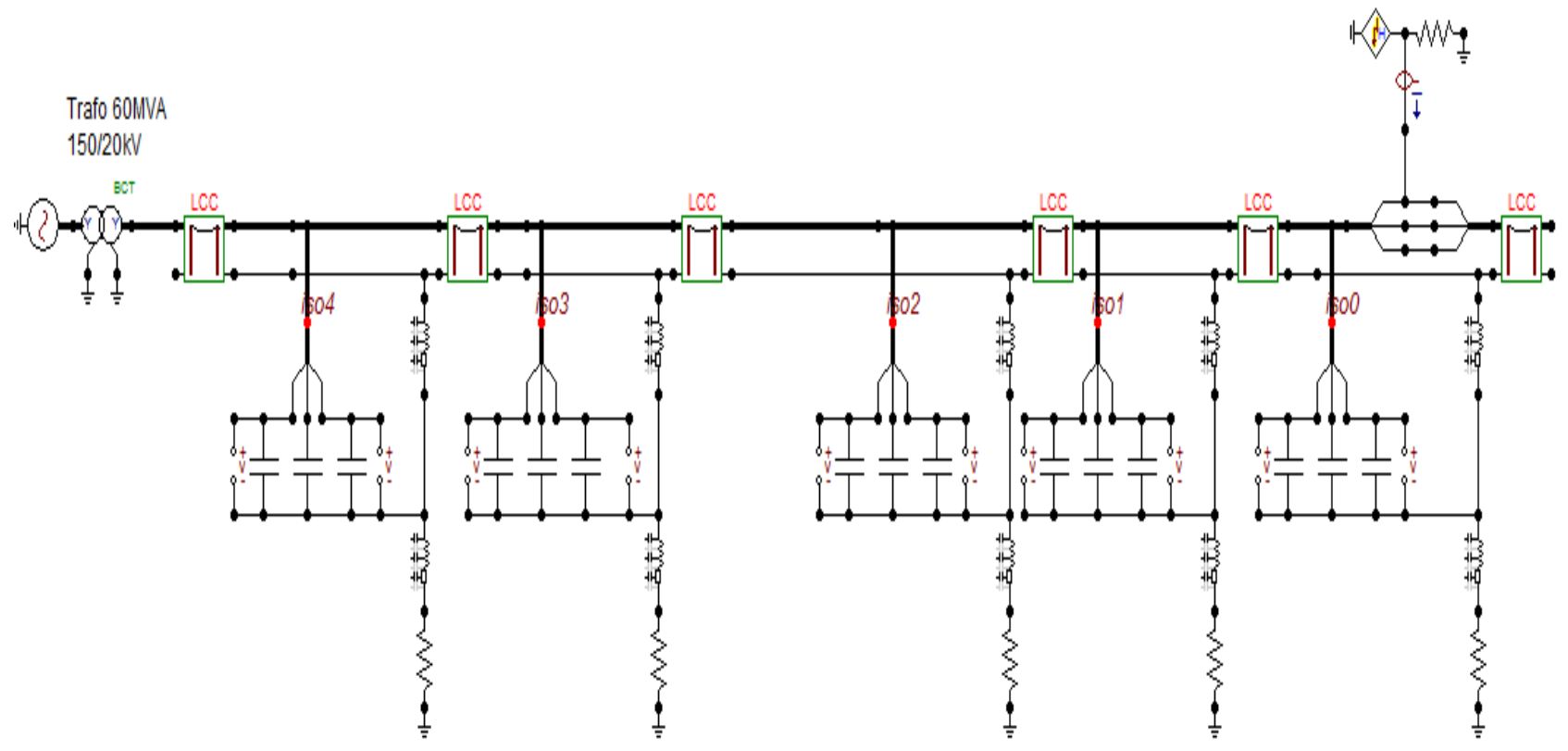

Fig. 5. Model for lightning simulation for distribution line with ground wire.

The simulation result for lightning strike on phase when the distribution line had ground wire is given in Table 1 and Table 2.

Table 1. Maximum overvoltage magnitude when negative polarity lightning stroked on phase A directly.

\begin{tabular}{|c|c|c|c|c|c|}
\hline \multirow{4}{*}{ Phase } & \multicolumn{5}{|c|}{ Maximum voltage magnitude (kV) } \\
\cline { 2 - 6 } & $\begin{array}{c}\text { at } \\
\text { striking } \\
\text { point }\end{array}$ & $\begin{array}{c}\text { one span } \\
\text { distance } \\
\text { from } \\
\text { striking } \\
\text { point }\end{array}$ & $\begin{array}{c}\text { two span } \\
\text { distance } \\
\text { from } \\
\text { striking } \\
\text { point }\end{array}$ & $\begin{array}{c}\text { three } \\
\text { span } \\
\text { distance } \\
\text { from } \\
\text { striking } \\
\text { point }\end{array}$ & $\begin{array}{c}\text { four } \\
\text { span } \\
\text { distance } \\
\text { from } \\
\text { striking } \\
\text { point }\end{array}$ \\
\hline $\mathrm{R}$ & 800 & 780 & 770 & 750 & 720 \\
\hline $\mathrm{S}$ & 200 & 210 & 240 & 230 & 210 \\
\hline $\mathrm{T}$ & 140 & 150 & 160 & 150 & 140 \\
\hline
\end{tabular}

Table 2. Maximum overvoltage magnitude when positive polarity lightning stroked on phase A directly.

\begin{tabular}{|c|c|c|c|c|c|}
\hline \multirow{2}{*}{ Phase } & \multicolumn{5}{|c|}{ Maximum voltage magnitude (kV) } \\
\cline { 2 - 6 } & $\begin{array}{c}\text { at } \\
\text { striking } \\
\text { point } \\
\text { one span } \\
\text { distance } \\
\text { from } \\
\text { striking } \\
\text { point }\end{array}$ & $\begin{array}{c}\text { two } \\
\text { spans } \\
\text { distance } \\
\text { from } \\
\text { striking } \\
\text { point }\end{array}$ & $\begin{array}{c}\text { three } \\
\text { spans } \\
\text { distance } \\
\text { from } \\
\text { striking } \\
\text { point }\end{array}$ & $\begin{array}{c}\text { four } \\
\text { spans } \\
\text { distance } \\
\text { from } \\
\text { striking } \\
\text { point }\end{array}$ \\
\hline R & 1040 & 1000 & 1100 & 1100 & 1100 \\
\hline S & 270 & 280 & 300 & 310 & 310 \\
\hline T & 200 & 200 & 220 & 230 & 220 \\
\hline
\end{tabular}

Table 1 and Table 2 present the voltage dynamic that occur across the isolator of Phase A, phase B, and phase $\mathrm{C}$, respectively for each different distance of striking point. Table 1 and Table 2 are obtained when the negative and positive polarity lightning magnitude were $3.32 \mathrm{kA}$. The simulation results for lightning strike on ground wire when the distribution line had ground wire is given in Table 3 and Table 4.

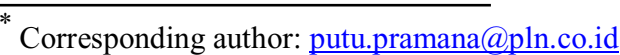

Table 3. Maximum overvoltage magnitude when negative polarity lightning stroked on ground wire.

\begin{tabular}{|c|c|c|c|c|c|}
\hline \multirow{2}{*}{ Phase } & \multicolumn{5}{|c|}{ Maximum voltage magnitude (kV) } \\
\cline { 2 - 6 } & $\begin{array}{c}\text { at } \\
\text { striking } \\
\text { point }\end{array}$ & $\begin{array}{c}\text { one span } \\
\text { distance } \\
\text { from } \\
\text { striking } \\
\text { point }\end{array}$ & $\begin{array}{c}\text { two } \\
\text { spans } \\
\text { distance } \\
\text { from } \\
\text { striking } \\
\text { point }\end{array}$ & $\begin{array}{c}\text { three } \\
\text { spans } \\
\text { distance } \\
\text { from } \\
\text { striking } \\
\text { point }\end{array}$ & $\begin{array}{c}\text { four } \\
\text { spans } \\
\text { distance } \\
\text { from } \\
\text { striking } \\
\text { point }\end{array}$ \\
\hline $\mathrm{R}$ & 70 & 25 & 23 & 25 & 27 \\
\hline $\mathrm{S}$ & 45 & 15 & 15 & 18 & 19 \\
\hline $\mathrm{T}$ & 45 & 15 & 15 & 18 & 19 \\
\hline
\end{tabular}

Table 3. Maximum overvoltage magnitude when positive polarity lightning stroke on ground wire.

\begin{tabular}{|c|c|c|c|c|c|}
\hline \multirow{3}{*}{ Phase } & \multicolumn{5}{|c|}{ Maximum voltage magnitude $(\mathrm{kV})$} \\
\cline { 2 - 6 } & $\begin{array}{c}\text { at } \\
\text { striking } \\
\text { point } \\
\text { one span } \\
\text { distance } \\
\text { from } \\
\text { striking } \\
\text { point }\end{array}$ & $\begin{array}{c}\text { two } \\
\text { spans } \\
\text { distance } \\
\text { from } \\
\text { striking } \\
\text { point }\end{array}$ & $\begin{array}{c}\text { three } \\
\text { spans } \\
\text { distance } \\
\text { from } \\
\text { striking } \\
\text { point }\end{array}$ & $\begin{array}{c}\text { four } \\
\text { spans } \\
\text { distance } \\
\text { from } \\
\text { striking } \\
\text { point }\end{array}$ \\
\hline $\mathrm{R}$ & 600 & 120 & 100 & 120 & 150 \\
\hline $\mathrm{S}$ & 580 & 100 & 100 & 120 & 120 \\
\hline $\mathrm{T}$ & 580 & 100 & 100 & 120 & 120 \\
\hline
\end{tabular}

Table 3 and Table 4 present the voltage dynamic that occur across the isolator of Phase A, phase $\mathrm{B}$, and phase $\mathrm{C}$, respectively for each different distance of striking point. The results in Table 3 and Table 4 are obtained when the negative and positive polarity lightning magnitude were $11 \mathrm{kA}$ and $23 \mathrm{kA}$, respectively.

\subsection{Power Arc Device (PAD) Simulation and Testing}

Besides the simulation of ground wire utilization to reduce the probability of lightning strike, the simulation 
and testing are also performed to study the characteristic of power arc device (PAD) utilization. PAD is used to anticipate the arcing event which flowing from the pinhole to the isolator ground, when an overvoltage occurred due to the lightning strike. The design of PAD is look like an arcing horn that has a function to channel the short circuit current to prevent the burn down of CC. The simulation of voltage stress when the PAD is implemented is given in Figure 5.

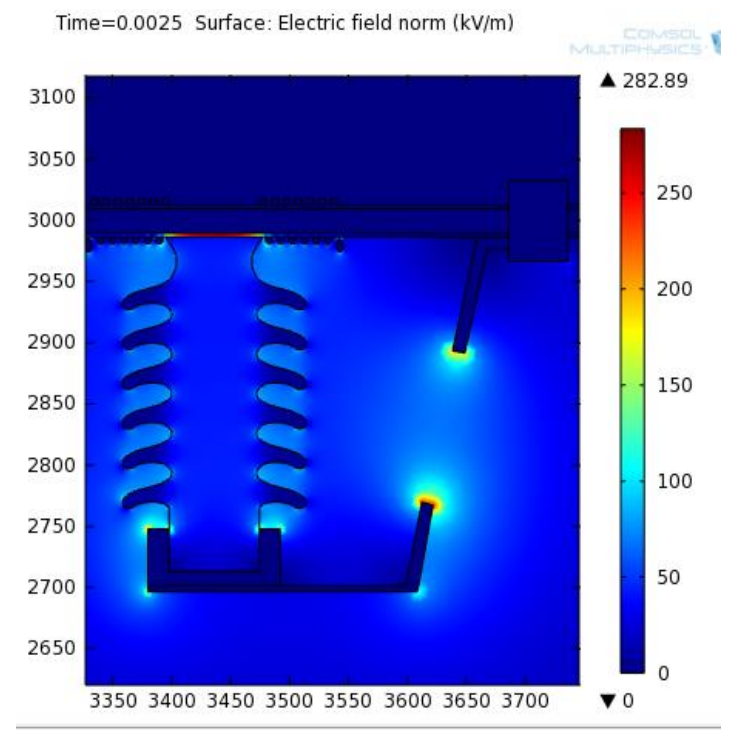

Fig. 5. PAD simulation based on finite element analysis.

Figure 5 shows the voltage stress distribution when the PAD is implemented on the $\mathrm{CC}$. The maximum voltage stress occur in the PAD ends so that when the overvoltage occurred thus the arcing current will flow through the PAD instead through the pinhole. To verify the simulation result, the testing of PAD utilization is also performed. The testing is carried out by introduce overvoltage and over current to the $\mathrm{CC}$, then the path of arc current is observed. The testing result of PAD utilization is given in Figure 6.

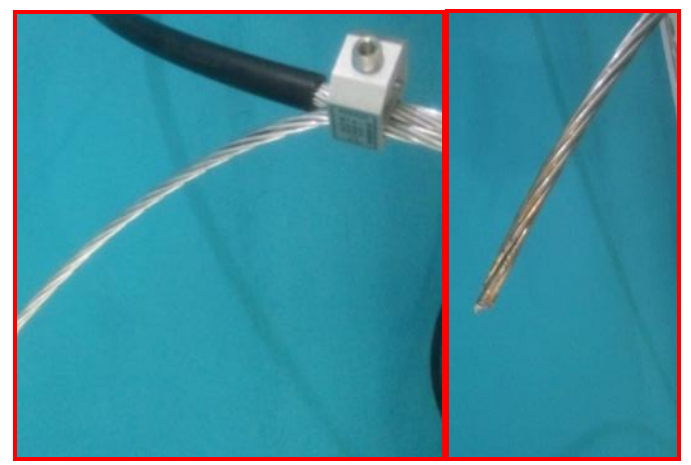

Fig. 6. PAD testing result

Figure 6 shows the melting trace on the PAD ends due to the arc current which flow to the ground during the overvoltage and short circuit condition. It can be known that although the overvoltage is happened, the short circuit current did not broke the CC.

\section{Discussion}

In the existing condition of distribution line as given in the first scenario (Figure 2), when the lightning strike occurred, it will strike directly to the phase wire. Therefore, overvoltage that exceeds the Basic Insulation Level (BIL) of the insulator is occurred. In this condition, when there was a pinhole near the insulator, the arc current will flow through the pinhole and a phase to ground fault is occurred. When it happened with a certain mechanical tensile, it will burn the $\mathrm{CC}$ down.

By the utilization of ground wire on the distribution line, it will create the protection angle and prevent the phase from the direct strike of the lightning. On the second scenario simulation, it is assumed that the cross arm length is about $0.8 \mathrm{~m}$, the ground wire and the phase wire height is about $14 \mathrm{~m}$ and $12 \mathrm{~m}$ from the ground, respectively. By this dimension of distribution pole, it can be calculated that the maximum lightning current that can directly strike the phase is about $3.32 \mathrm{kA}$, both for the positive and negative polarity of lightning.

By using the ground wire, when the lightning stroked the ground wire, the probability of overvoltage that can exceed the insulator BIL is still present, i.e. when the lightning polarity is positive. However, if the lightning strike has negative polarity, then the lightning current of $11 \mathrm{kA}$ (the mode value of negative lightning current magnitude) will not cause overvoltage exceeding the BIL isolator. In addition, the probability of a positive lightning appearance is relatively small compared to the probability of negative lightning, i.e. only $11 \%$ of all strokes are positive lightning.

If the direct strike to the phase occurs when the ground wire has been used, then the lightning current $(3.32 \mathrm{kA})$ will produce a voltage exceeding the BIL of the insulator. However, the condition of lightning strike with a maximum magnitude of $3.32 \mathrm{kA}$ is very small that only about $1 \%$ refers to the distribution of lightning distribution in Figure 1.

However, when the overvoltage due to the lightning strike occurs, PAD serves to prevent the flow of shortcircuit (arcing) through the pinhole to the ground. This can happen because the maximum voltage stress will occur between the two ends of the PAD, as in Figure 5. Thus, when there was overvoltage due to lightning strikes, short circuit flows through PAD ends by leaving a melting trace, without burning the $\mathrm{CC}$ down, as shown in Figure 6.

\section{Conclusion}

The utilization of ground wire reduces the lightning strike probability to the phase conductor. The lightning strike on the ground wire with negative polarity will not cause transient overvoltage with a magnitude greater than the insulator BIL. However, if the lighting strikes have positive polarity, then the insulator BIL will be potentially exceeded. In addition, the utilization of power arc device will prevent the covered conductor burn down. 


\section{References}

1. Ronaldo E. de Souza, Rafael M. Gomes, Guilherme S. Lima, Fernando H. Silveira, Alberto De Conti, and Silvério Visacro, Preliminary analysis of the impulse breakdown characteristics of XLPE-covered cables used in compact distribution lines International Conference on Lightning Protection, Estoril, Portugal, (2016)

2. K. Nakamura, P.J. McKenny, and M.S.A.A. Hammam, G. Adams, R. Fernandes, and F. Rushden, IEEE Transactions on Power Delivery, Vol. PWRD-1, No. 4, October (1986)

3. Narong Mungkung, Tanes Tanitteerapan,Werachai Chaokumnerd, Karun Morasilp, Panumat Limsuwan, Warawut Poolperm and Toshifumi Yuji, Problem Solving of Partial Discharge on The Distribution Line, WSEAS TRANSACTIONS on POWER SYSTEMS, Issue 1, Volume 4, January (2009)

4. A. A. Ostsemin, Melting Rate of Electrode Wire in Arc Welding, Russian Engineering Research, 2010, Vol. 30, No. 7, pp. 677-679. Allerton Press, Inc., (2010)

5. Amin Ghaderia, Herbert L. Ginn III, Hossein Ali Mohammadpour, High impedance fault detection: A review, Electric Power Systems Research 143, 376388, (2017)

6. B. Michael Aucoin dan Robert H. Jones, High Impedance Fault Detection Implementation Issues, IEEE Transactions on Power Delivery, Vol. 11, No. 1, January (1996)

7. IEEE Guide for Recommended Electrical Clearances and Insulation Levels in Air-Insulated Electrical Power Substation, in IEEE Std 1427-2006, vol., no., pp. C1-40, May 4 (2007)

8. T. Ito, T. Ueda, H. Watanabe, T. Funabashi and A. Ametani, Lightning flashovers on $77-\mathrm{kV}$ systems: observed voltage bias effects and analysis, in IEEE Transactions on Power Delivery, vol. 18, no. 2, pp. 545-550, April (2003) 